\title{
Desafios da sociedade da informação
}

\section{Christiana Freitas}

\section{Tom Dwyer}

O segundo número do Liinc em Revista tem como objetivo apresentar temas que estimulem o debate em torno de questões referentes a transformações observadas nas diversas esferas da sociedade com a utilização e incorporação das tecnologias da informação.

Ao longo do século XX houve um grande aumento nas comunicações entre as pessoas; na última parte do século este movimento acelerou-se através do desenvolvimento de tecnologias de informação e comunicação (TICs). Há um processo de aprendizagem do uso destes meios sem que as pessoas levantem muitas questões sobre o que existe por trás 'Comunicar mais' parece fazer parte do mundo moderno, mas isto certamente não quer dizer que comunicamos melhor. Nas democracias contemporâneas, e o Brasil é uma das maiores delas, aumentar a velocidade de transmissão e do volume tanto de comunicação quanto de informação parece ser um valor universal. Cientistas, juízes, cidadãos comuns usam os espaços abertos pelas TICs para se organizar e para se informar. É necessário observar isto empiricamente. Como as pessoas agem? Como estas ações se diferenciam de grupo a grupo, de país a país?

É preciso perguntar também por que as TICs são tão bem avaliadas por quase todas as categorias de atores sociais enquanto outras tecnologias de informação, e especialmente as de manipulação genética aplicada à comida, centrais nucleares e outras são tão mal recebidas? A resposta parece ser que a comunicação e a informação fazem parte de uma utopia construída, uma extensão do iluminismo. É preciso fazer análises precisas e empíricas e também ver como estas análises afetam a construção da ação dos outros, sejam cidadãos que se manifestam contra transgênicos ou cidadãos que aderem à causa zapatista. Os trabalhos apresentados neste número da revista constituem uma amostra da pesquisa acadêmica nesta nova área de estudos. Quase todos os pesquisadores neste campo são motivados pela idéia de que o futuro do Brasil será cada vez mais um futuro informacional. Que é necessário mobilizar uma variedade de teorias e metodologias para estudar os fenômenos que se apresentam. Há trabalhos mais teóricos e até filosóficos sobre a natureza do mundo novo que se forma e do futuro da humanidade dentro disso. A sociedade de informação é portadora do futuro e para interpretá-la são necessárias boas descrições e análises. A maioria dos artigos, marcados por diálogos interdisciplinares, se baseia em pesquisas empíricas sobre dimensões específicas dos fenômenos em questão. Há também reflexões de natureza mais teórica, que buscam ajudar a repensar o mundo que se transforma ao nosso redor.

Nos artigos que seguem é possível observar que o campo de investigação é aberto, não sujeito a ortodoxias, que os autores bebem de uma grande variedade de fontes bibliográficas e que temos várias linhas de inquérito e poucas visões consolidadas ou escolas. Ainda mais, os autores travam diálogos com os debates e a bibliografia internacional.

Abrimos este número da revista com um artigo que instiga o debate e a reflexão crítica acerca da Sociedade da Informação ou Sociedade do Conhecimento. Aécio Amaral apresenta, em seu artigo sobre tecnologia, experiência e memória, uma análise da relação entre memória e escritura, corpo e arquivo na contemporaneidade. Interessante perceber as possíveis armadilhas de um humanismo "tecnofóbico" e a gradual transformação e superação da concepção dicotômica que tende a separar corpo humano e aparato tecnológico. Que fronteiras e limites ainda existem, se é que existem? 
Pedro Demo reacende o debate, interessante e necessário, sobre as possibilidades e desafios com os quais se depara a humanidade quando há interação com os computadores. Que desafios seriam esses? Seriam as máquinas capazes de manipular a expressão das idéias ou, o que seria mais surpreendente, as próprias idéias? Que espaço teriam na contemporaneidade? A partir das idéias de Hillis, o autor tece considerações críticas fundamentais para o debate atual, evitando conclusões ingênuas e precipitadas como as de tantos autores que tratam do tema.

Cecilia Diaz-Isenrath apresenta um estudo sobre o Google que tem, como preocupação central, as relações entre humanos e máquinas. O motor de busca em questão é visto não como uma mera ferramenta informacional, mas como um dispositivo sóciotécnico, com todas as implicações que o conceito engendra. Significa dizer que o aparato é analisado como um conjunto de recursos tecnológicos que existe de uma determinada forma dado seu caráter não apenas técnico, mas também social. A construção do artefato não diz respeito apenas à mobilização de recursos, mas também à organização de um complexo que favoreça a adesão de aliados e a conjugação de elementos sócio-políticos que garantam o sucesso da iniciativa.

Em seguida, o artigo de Roberto Fragale e Fernando Fontainha propõe questões essenciais para discussão a partir da análise do fenômeno da informatização dos tribunais brasileiros. Os autores resgatam conceitos teóricos essenciais à compreensão da contemporaneidade, como o conceito de modernidade reflexiva formulado por Ulrich Beck. Especialmente interessante é a análise acerca dos riscos globais aos quais nos expomos ao submeter parte da administração de nossas relações coletivas a recursos computacionais virtuais.

Novas práticas e costumes são observados no artigo apresentado por Marta Pinheiro e Mauro Câmara a respeito da instalação de telecentros em distritos de Minas Gerais. Os autores analisam a iniciativa, que surge como proposta de inclusão digital de grupos marginalizados, implicando uma série de transformações nas relações e práticas sociais vividas nos locais em que foram instalados os telecentros. A iniciativa é vista como uma possível opção para a superação e rompimento da "cadeia de reprodução de pobreza" que se observa nesses locais. Entretanto, como bem observam os autores, não basta a formulação de políticas e programas de inclusão digital. Tais iniciativas devem estar atentas às especificidades sócio-culturais de cada grupo a ser atingido, permitindo, assim, a construção de uma sociedade do conhecimento que, de fato, promova a inclusão.

O artigo de Gilson Lima alerta para o fato de lidarmos, atualmente, com infra-estruturas reflexivas de informação e comunicação digital capazes de replicar reflexividades miméticas ou representações imitadas; ainda assim, não são sinônimos de conhecimento complexo ou de uma nova modulação de conhecimento. $\mathrm{O}$ autor reafirma o fato de as tecnologias de informação e comunicação possibilitarem, em contrapartida, uma gama quase infinita de amplificadores cognitivos a serem exercidos de forma simbiótica, facilitando significativamente a produção de conhecimento na sociedade contemporânea.

Por fim, temos a resenha de Hans-Jürgen Michalski sobre o livro "A empresa sem limites". Várias críticas pertinentes às afirmações do livro são apresentadas, como a necessidade de análise cautelosa da afirmação de uma suposta dissolução dos limites hierárquicos nas empresas, resultado da existência de uma nova forma organizacional. Outras questões são tratadas com o mesmo rigor, como o conceito de "mercados eletrônicos", "tele-cooperação" e "empresas virtuais".

Esperamos, com este segundo número, contribuir para suscitar o debate a respeito de questões tão prementes da contemporaneidade. 